\title{
Enhanced E-layer ionization in the auroral zones observed by radio occultation measurements onboard CHAMP and Formosat-3/COSMIC
}

\author{
C. Mayer and N. Jakowski \\ German Aerospace Center, Institute of Communications and Navigation, Kalkhorstweg 53, 17235 Neustrelitz, Germany
}

Received: 20 December 2007 - Revised: 21 July 2008 - Accepted: 16 September 2008 - Published: 10 March 2009

\begin{abstract}
Particle precipitation of magnetospheric origin causes additional ionization in the auroral zone at E-layer heights. During night-time, in particular at winter-night, the E-layer ionization may dominate over the F2-layer ionization level. To study the geophysical conditions and characteristics of the related ionospheric processes in more detail, we use GPS radio occultation electron density profile retrievals from CHAMP and Formosat-3/COSMIC to extract those vertical profiles which show the absolute maximum of ionization in the E-layer height range of $90-150 \mathrm{~km}$. In order to select these profiles, we have developed an algorithm which can recognize the shape of a given profile by fitting an empirical Ansatz to it. Using data from CHAMP collected since 2002 and Formosat-3/COSMIC data starting from 2006, we are able to study both, the local-time dependence and the solarcylce variability of the observed processes.
\end{abstract}

Keywords. Ionosphere (Polar ionosphere; Instruments and techniques) - Radio science (Ionospheric physics)

\section{Introduction}

Measuring the signal phase of GPS satellites onboard Low Earth Orbiting (LEO) satellites in the limb sounding mode during the rising or declining phase, the vertical refractivity profile of the ionosphere and atmosphere can be deduced from the orbit height down to the Earth surface, respectively. Since the index of refractivity of the ionosphere depends mainly on the number of free electrons, the inversion of the measured signals can provide the vertical electron density profile (e.g. Hajj and Romans, 1998; Schreiner et al., 1999; Jakowski et al., 2002). Radio occultation measurements onboard CHAMP have been used since April 2002 to retrieve

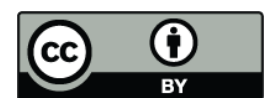

Correspondence to: C. Mayer (christoph.mayer@dlr.de) vertical electron density profiles on a routine basis. The automatically processed profiles (Wehrenpfennig et al., 2001) are available via the DLR space weather service SWACI (2007). More than 200000 profiles have been retrieved so far by using a model assisted retrieval technique (Jakowski, 2005). Validation with mid-latitude ionosonde stations in Europe provided reasonable results with an RMS error of about $1 \mathrm{MHz}$ throughout the entire profile (Jakowski et al., 2005).

While the electron density profiles derived from CHAMP occultations cover a long period of time, the six Formosat3/COSMIC satellites, launched in April 2006, provide a unprecedented data coverage for detailed studies of the vertical ionospheric structure (e.g. Rocken et al., 2000; Schreiner et al., 2009). The comparison of CHAMP electron density profiles with electron density profiles deduced from the radio occultation measurements onboard the Formosat3/COSMIC satellites, which are provided by the data center TACC/CDAAC, revealed good agreement with a RMS of less than $1.4 \times 10^{11} \mathrm{~m}^{-3}$ for $N m \mathrm{~F} 2$, cf. Jakowski et al. (2006). The six Formosat-3/COSMIC satellites are in orbits between $600 \mathrm{~km}$ and $800 \mathrm{~km}$ height and provide up to 2500 globally distributed electron density profiles each day, both from rising and setting GPS occultations.

The achieved accuracy in retrieving vertical electron density profiles allowed us to select those profiles having the peak density in E-layer heights between 90 and $150 \mathrm{~km}$ at higher latitudes. The high latitude E-layer, in particular within the auroral oval, is strongly influenced by particle ionization, whereas auroral ion precipitation is, on average, situated equatorward of electron precipitation, (Jayachandran et al., 2002; Hardy et al., 1991). Following the above mentioned selection rule, we do not distinguish between these different types of ionization or sporadic E-layer formation. Therefore, the selected vertical electron density profiles simply refer to an "E-layer dominated ionosphere" (ELDI).

Published by Copernicus Publications on behalf of the European Geosciences Union. 


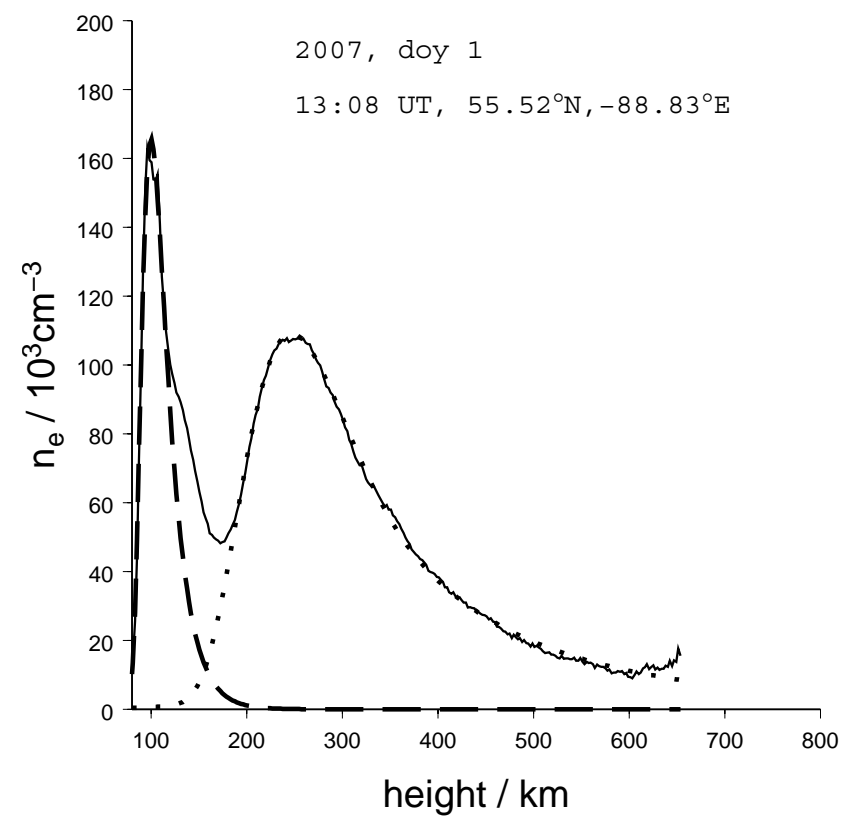

Fig. 1. Shown is a Formosat-3/COSMIC profile (solid line) with E-layer dominating ionosphere and the E-layer (dashed) and Flayer/topside (dotted) functions resulting from the fit explained in Sect. 2.

\section{Profile recognition}

In this section, we explain how we recognize electron density profiles by fitting suitable functions to the profiles in the Flayer/topside ${ }^{1}$ and E-layer height range. Then we can assess the profile using information of the fit such as its convergence and residuals $\left(\chi^{2}\right)$.

\subsection{F-layer and topside}

For the F-region and the topside part of a given electron density profile we use an empirical Ansatz consisting of an $(\alpha-)$ Chapman layer function and an exponentially decreasing topside approximation,

$f^{F, \text { top }}(h)=p_{\text {iono }}(h) f^{\mathrm{F}}(h)+p_{\text {top }}(h) f^{\text {top }}(h)$,

with the Chapman layer function defined as,

$f^{\mathrm{F}}(h)=N_{F} \exp \left\{\frac{1}{2}[1-z-\exp (-z)]\right\}$,

with $z=\frac{h-h_{F}}{H_{F}}$, and the topside approximation,

$f^{\text {top }}(h)=N_{\text {top }} \exp \left\{-\frac{h-h_{\text {top }}}{H(h)}\right\}$,

\footnotetext{
${ }^{1}$ Note that we consider the topside part of the electron density files, although, for the purpose of this paper which focuses on enhanced E-layer ionization, it is not strictly neccessary.
}

Table 1. Statistics of the profile recognition algorithm. We have used CHAMP and Formosat-3/COSMIC electron density profiles in the Northern Hemisphere in north winter, i.e. doy $>330$ or doy $<60$, and latitude $>45^{\circ} \mathrm{N}$. The total number of available profiles, the number of bad profiles which were excluded from the analysis, and the number of profiles with ELDI signature are shown.

\begin{tabular}{llrrr}
\hline Satellite & Period & total & excluded & ELDI \\
\hline Formosat-3 & $2006.030-2007.059$ & 40867 & 882 & 3961 \\
CHAMP & $2001.300-2002.059$, & 6233 & 3 & 115 \\
& $2002.300-2003.059$ & & & \\
CHAMP & $2005.300-2006.059$, & 6809 & 6 & 747 \\
& $2006.300-2007.059$ & & & \\
\hline
\end{tabular}

with a linearly varying topside scale height,

$H(h)=H_{\text {top }}+a_{\text {top }}\left(h-h_{\text {top }}\right)$.

Between these functions a smooth interpolation is performed by using the smooth "step functions",

$p_{\text {iono,top }}(h)=\frac{1}{2}\left[1 \mp \tanh \left(\frac{h-h_{p}}{H_{p}}\right)\right]$.

We would like to mention that another way of connecting a Chapman layer function to the topside is the vary-chap Ansatz of Reinisch et al. (2007). Since the function $f^{F, \text { top }}(h)$ depends on nine parameters, $N_{F}, h_{F}, H_{F}, N_{\text {top }}, h_{\text {top }}, H_{\text {top }}$, $a_{\text {top }}, h_{p}$, and $H_{p}$, we fix

$h_{\text {top }}=h_{p}, \quad H_{p}=75 \mathrm{~km}, \quad N_{\text {top }}=f^{\text {ch }}\left(h_{\text {top }}\right)$,

in order to reduce the number of unknowns.

As the function $f^{f \text {,top }}(h)$ depends in a non-linear way on the parameters we use a non-linear least squares optimization algorithm (Markwardt and Rivers, 2008) which is adapted from the FORTRAN77 MINPACK software.

\subsection{E-layer}

For the E-layer we fit the Chapman layer function (Eq. 2) to the profile in the range of 80 to $150 \mathrm{~km}$. Figure 1 shows a well-fitted Formosat-3/COSMIC profile with clearly separated $\mathrm{E}$ and $\mathrm{F}$-layers.

\section{Data analysis}

After applying the procedure described in Sect. 2 to Formosat-3/COSMIC and CHAMP electron density profiles, we have selected profiles which indicate an "E-layer dominated ionosphere" according to

$N m \mathrm{E}>N m \mathrm{~F}, \quad(\mathrm{ELDI})$.

In this study we use only profiles located in the Northern Hemisphere, latitude $>45^{\circ} \mathrm{N}$, and we impose the conditions 

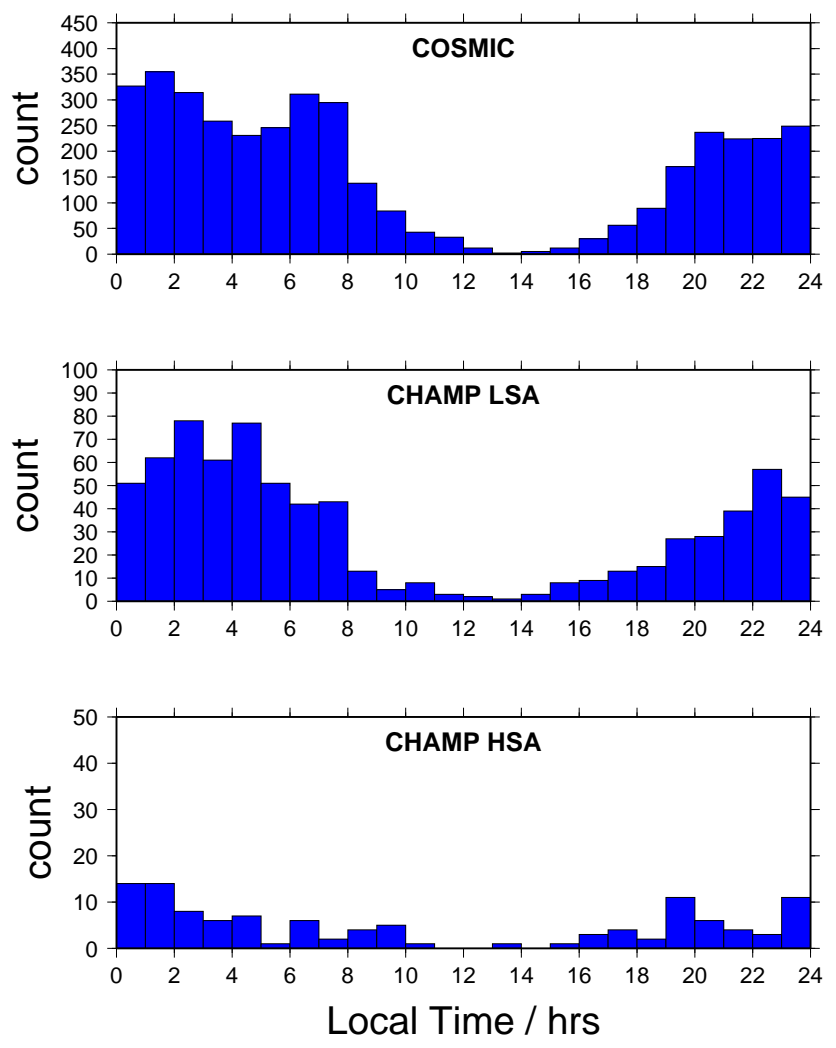

Fig. 2. Local time dependence of Formosat-3/COSMIC profiles which statisfy the ELDI condition. Top: Formosat-3/COSMIC profiles, middle: CHAMP profiles from the period 2005/06 with low solar activity (LSA) and bottom: CHAMP profiles from 2002/03 at high solar activity (HSA).

$H_{E}<40 \mathrm{~km}$ (with $H_{E}$ denoting the chapman E-layer scale hight) and the statistical quality check $\chi^{2} /$ dof $<1$.

Table 1 summarizes the data basis used in this paper and the performance of our profile recognition algorithm. The number of bad profiles for which the analysis with the profile cognition algorithm fails is less than $2.1 \%$ for Formosat$3 /$ COSMIC profiles, and less than $0.1 \%$ for CHAMP profiles.

\subsection{Spatial and temporal relationships}

In Fig. 3 we plot the geographical locations of Formosat3/COSMIC profiles which satisfy Eq. (7) on the Northern Hemisphere. The selected profiles seem to be distributed along the auroral oval.

In the northern winter season ELDI profiles occur at high latitudes in the local night-time, showing two maxima at 01:00 LT and 07:00 LT, cf. Fig. 2.

In order to study the solar-cycle dependence of the occurrence of ELDI profiles, we have analysed CHAMP profiles from the winter of 2002/2003 and 2006/2007. As Fig. 2 shows, the local-time dependence is similar to the selected Formosat-3/COSMIC profiles. Note that near the solar-cycle

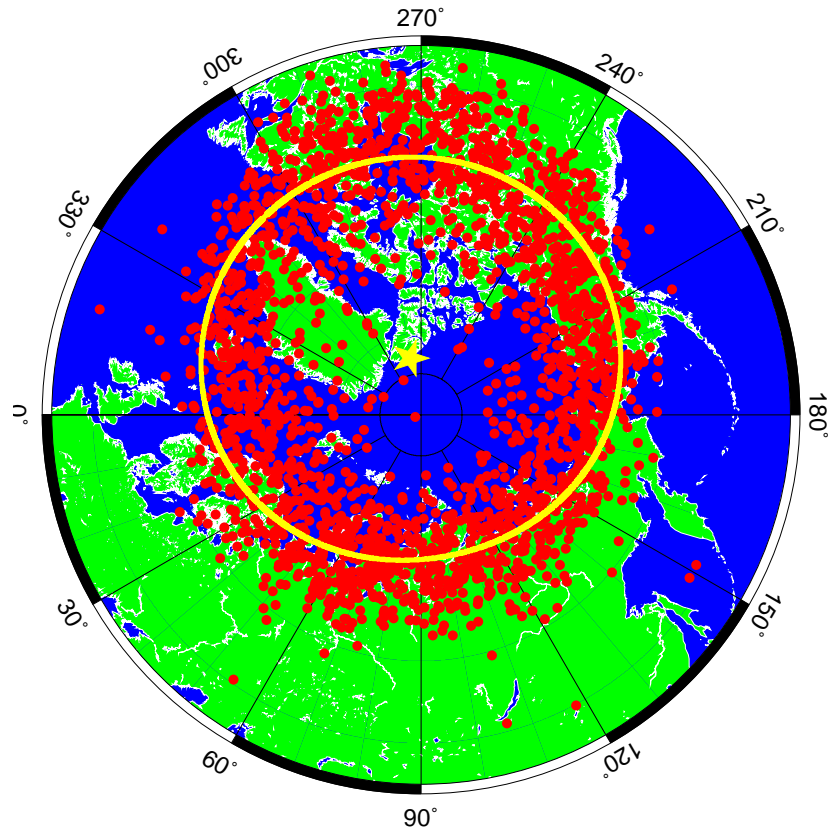

Fig. 3. Circle fit to the distribution of Formosat-3/COSMIC profiles which statisfy the ELDI condition. The yellow star marks the center of the circle fitted to the data, which coincides with the geomagnetic pole.

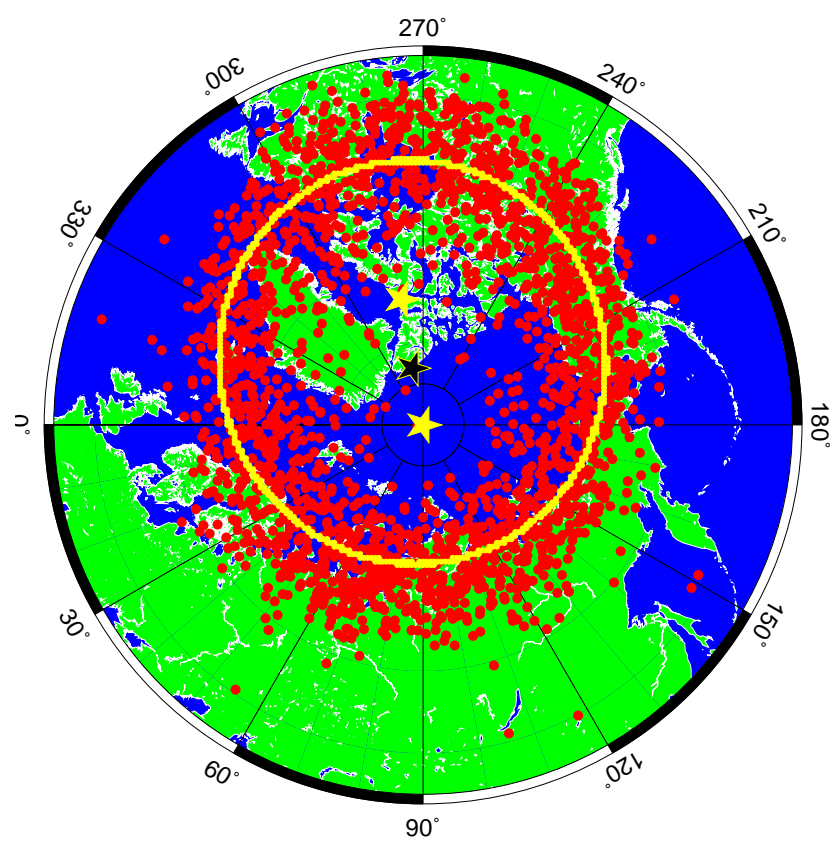

Fig. 4. Ellipse fit to the distribution of Formosat-3/COSMIC profiles which statisfy the ELDI condition. The yellow stars mark the focal points of the ellipse, the black star marks the center point of the circle fit. 


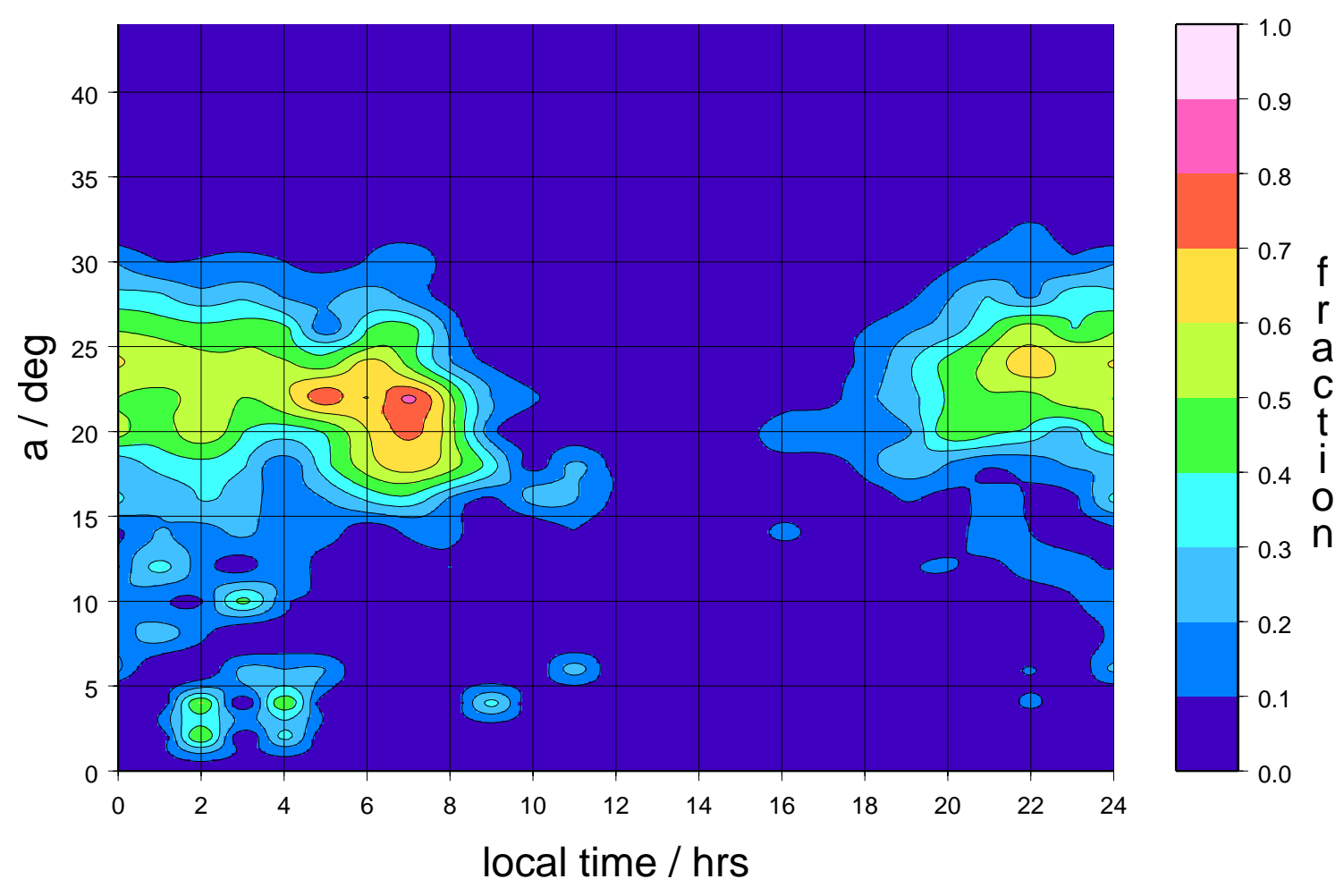

Fig. 5. Density distribution of Formosat-3/COSMIC profiles which statisfy the ELDI condition for quiet geomagnetic conditions, $A_{p} \leq 10$.

minimum, 2006/07, there are much more ELDI profiles than near its maximum 2001/02.

\subsection{Relation to the auroral oval}

If the radio occultation profiles with an ELDI signature are related to polar particle preciptiation, we expect the profile distribution in Fig. 3 to be centered around the geomagnetic pole. Instead of using geomagnetic coordinates, we approximate the distribution of profiles first by a circle and next by an ellipse using a non-linear fit to the geographic profile positions. For comparison, an auroral oval model using a fourier series in geomagnetic coordinates is discussed in Feldstein (1963) and Holzworth and Meng (1975).

We have fitted the (3-D Cartesian) positions $\boldsymbol{x}_{i}$ of all selected ELDI profiles on the Northern Hemisphere with all local times to a circle, parameterized by its offset $\boldsymbol{p}$ from the geographical north pole and its radius $r$ by minimizing the cost function

$S_{\text {circle }}=\sum_{i}\left[\operatorname{acos}\left(\boldsymbol{x}_{i} \cdot \boldsymbol{p}\right)^{2}-r^{2}\right]^{2}$,

where we normalize all 3-vectors to unit length and take the latitude/longitude of $\boldsymbol{p}$ and $r$ as parameters to be determined by the non-linear fit. As a result we obtain

$p=\left(83.02^{\circ} \mathrm{N},-79.09^{\circ} \mathrm{E}\right), \quad r=24.68^{\circ}$, cf. Fig. 3. Note that $\boldsymbol{p}$ is close to the position of the geomagnetic pole, which, according to the IGRF model for the epoch 2007 , is at $\left(82.20^{\circ} \mathrm{N},-82.98^{\circ} \mathrm{E}\right)$ (IGRF CGM, 2008). Thus, in a first approximation, the selected profiles follow a circle around the geomagnetic pole.

In order to obtain a better approximation of the distribution of ELDI profiles, we fit the distribution of selected ELDI profiles to an ellipse, $E_{0}$, parameterized by the two focal points, $\boldsymbol{p}_{0}$ and $\boldsymbol{q}_{0}$, and the major axis parameter, $a_{0}$. Here, we minimize the cost function

$S_{\text {ellipse }}=\sum_{i}\left[\left|\operatorname{acos}\left(\boldsymbol{x}_{i} \cdot \boldsymbol{p}_{0}\right)\right|+\left|\operatorname{acos}\left(\boldsymbol{x}_{i} \cdot \boldsymbol{q}_{0}\right)\right|-2 a_{0}\right]^{2}$,

where again all 3-vectors have unit length. When we perform this non-linear fit, we obtain for the focal points $\boldsymbol{p}_{0}=\left(74.49^{\circ} \mathrm{N},-80.27^{\circ} \mathrm{E}\right), \boldsymbol{q}_{0}=\left(90.00^{\circ} \mathrm{N}\right)$ and for the major and minor axis parameters $a_{0}=24.61^{\circ}, b_{0}=23.36^{\circ}$, respectively. Note that the circle-fit magnetic pole position lies on the great-circle between $\boldsymbol{p}_{0}$ and $\boldsymbol{q}_{0}$ of the improved ellipse approximation, cf. Fig. 4 . It is interesting to note that one focal point fits very well to the geographic pole.

After transforming the ellipse into magnetic coordinates, we find that it matches the local magnetic night-time southward boundary given by the Feldstein representation of the auroral oval at midnight magnetic local time and at middle activity level 3, Feldstein et al. (2008), Feldstein (1963) and Holzworth and Meng (1975). For a discussion of different 


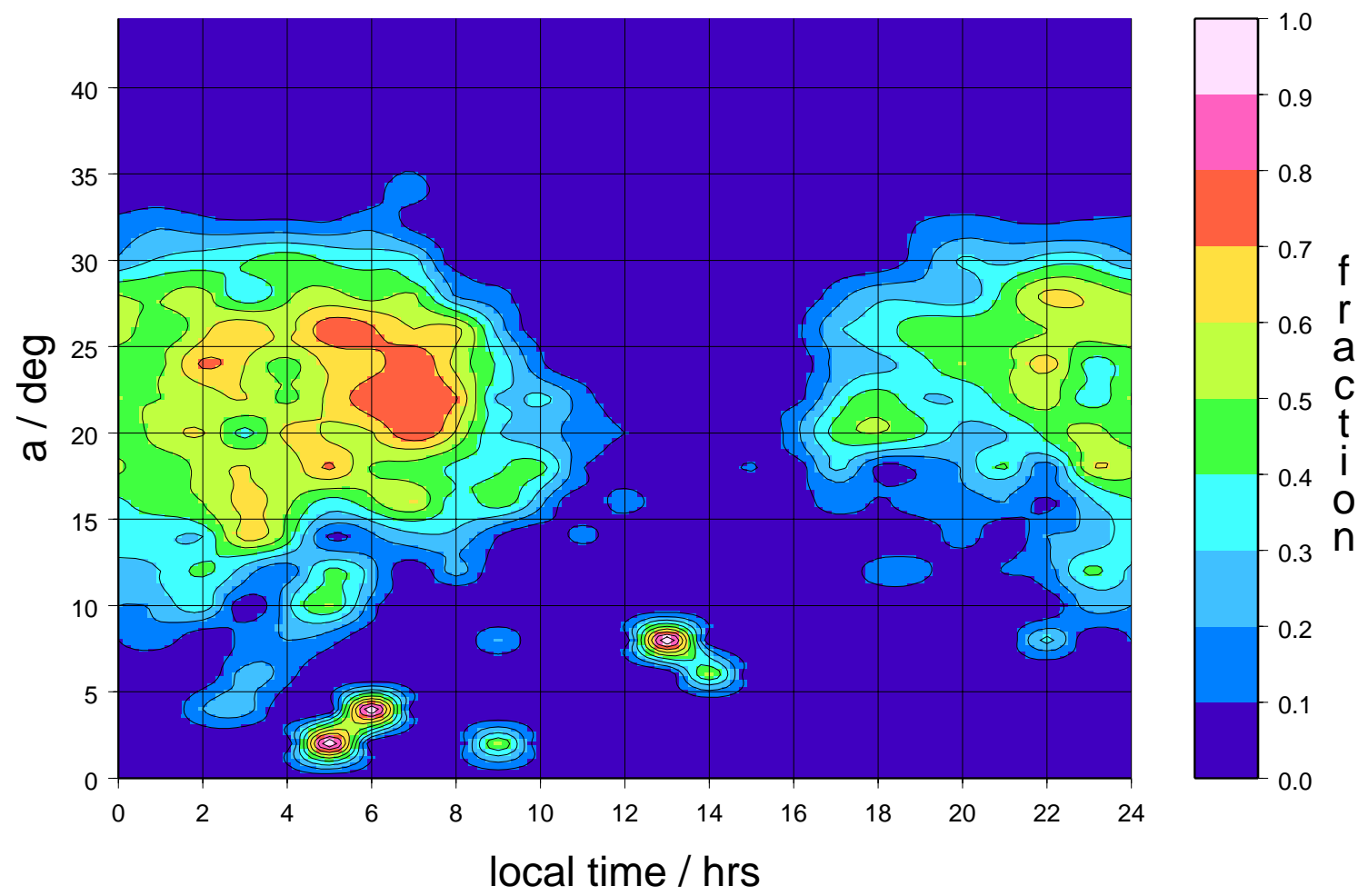

Fig. 6. Density distribution of Formosat-3/COSMIC profiles which statisfy the ELDI condition for disturbed geomagnetic conditions, $A_{p}>10$. The single patches at local noon and $5^{\circ}<a<10^{\circ}$ are due to enhanced day side particle precipitation during the proton events of December 2006.

auroral (boundary) models we refer to Szuszczewicz et al. (1993).

\subsection{Occurrence probablilty}

In order to calculate the probablity for finding an ELDI profile at position $\boldsymbol{x}$ and local time $t$, the following procedure is applied. Using the ellipse $E_{0}$ constructed in the last subsection as a reference, we construct a family of ellipses parameterized by the major axis parameter,

$a \mapsto E_{a}=[\boldsymbol{p}(a), \boldsymbol{q}(a), a]$,

which are centered on $E_{0}$. This implies that $\boldsymbol{p}$ and $\boldsymbol{q}$ lie on the great-circle determined by $\boldsymbol{p}_{0}, \boldsymbol{q}_{0}$. In this way we are able to associate with every profile position $\boldsymbol{x}$ an ellipse $E_{a}$ of the familiy defined in Eq. (11) with parameter $a(\boldsymbol{x})$.

In order to obtain the density distribution of ELDI profiles from the Formosat-3/COSMIC data sample, we compute the local time and ellipse parameter $a$ of each selected profile and bin the corresponding data into $1 \mathrm{~h} / 2^{\circ}$ bins. The resulting smoothed two-dimensional histogram is shown in Figs. 5 and 6 for $A_{p} \leq 10$ and $A_{p}>10$, respectively. Note that the probability of finding a profile with precipitation signature can be as high as $80 \%$ in the local morning hours between 07:00 and 08:00 local time.
As expected, there is a dependence of the profile distribution on the $A_{p}$ index. For $A_{p} \leq 10$ the distribution is localized in $a$, while for $A_{p}>10$ the distribution is shifted to larger values of $a$ and is broader in $a$, cf. Figs. 5, 6, due to enhanced pitch angle distribution of ionizing particles, see Khazanov et al. (2007).

\section{Conclusions}

We have shown that electron density profiles obtained by the GPS radio occultation method can be used to study the phenomenon of particle precipitation in high latitudes. In particular, the Formosat-3/COSMIC mission allows to investigate the polar ionosphere in great detail, while with CHAMP data we are able to investigate solar-cycle dependent effects.

Ionospheric radio occultation measurements from CHAMP and COSMIC/Formosat-3 indicate a significant number of ELDI profiles characterized by $N m \mathrm{E}>N m \mathrm{~F} 2$ distributed symmetrically around the magnetic pole. We obtain this result by a non-linear fit of a circle and subsequently of an ellipse to the spatial distribution of selected profiles, without using any prior information about the Earth's geomagnetic field. 
The shape of this distribution can be approximated by an ellipse. Using a family of ellipses the probability of observing an ELDI profile can be computed depending on local time and ellipse major axis parameter. This distribution may be used to create a model of the occurrence of the ELDI condition in the polar ionosphere, which would be useful, e.g. for HF propagation forecasts.

ELDI is a regular phenomenon in the nighttime auroral zone of the winter hemishere. Between 07:00 and 08:00 local time and $a$ between $20^{\circ}$ and $25^{\circ}$, up to $80 \%$ of all measured profiles show an ELDI signature.

During the proton events of December 2006 we have detected ELDI profiles close to the geomagnetic pole $\left(5^{\circ}<a<10^{\circ}\right)$ between 11:00 and 14:00 LT, indicating day side particle precipitation as described e.g. by Mende et al. (2001).

Acknowledgements. We thank the international teams of satellite missions CHAMP and Formosat-3/COSMIC for operating the satellites and providing the observation data. We greatfully acknowledge the provision and Formosat-3/COSMIC profile data from TACC/CDAAC. For the IGRF magnetic field model and the Feldstein auroral oval model we acknowledge SPDF/Modelweb and NSSDC. This work has been financially supported by the German State Government of Mecklenburg-Vorpommern under the Grant AU-07-008.

Topical Editor K. Kauristie thanks T. Jayachandran and another anonymous referee for their help in evaluating this paper.

\section{References}

Feldstein, Y. I.: On Morphology and Auroral and Magnetic Disturbances at High Latitudes, Geomagn. Aeron., 3, 227-239, 1963.

Feldstein, Y. I., Holzworth, R. H., and Meng, C.-I.: Feldstein/Holzworth/Meng Auroral boundary model, http://nssdcftp.gsfc.nasa.gov/models/ionospheric/auroral_oval/ feldstein_holzworth, last access November 2008.

Hajj, G. A. and Romans, L. J.: Ionospheric electron density profiles obtained with the Global Positioning System: Results from the GPS/MET experiment, Radio Sci., 33, 175-190, 1998.

Hardy, D. A., Gussenhoven, M. S., Brautigam, D., and McNeil, W.: A statistical model of auroral ion precipitation. II - Functional representation of the average patterns, J. Geophys. Res., 96, 5539-5547, 1991.

Holzworth, R. H. and Meng, C.-I.: Mathematical representation of the auroral oval, Geophys. Res. Lett., 2, 377-380, 1975.

IGRF CGM: http://modelweb.gsfc.nasa.gov/models/cgm/cgm. html, last access November 2008.

Jakowski, N., Wehrenpfennig, A., Heise, S., Reigber, Ch., Lühr, H., Grunwaldt, L., and Meehan, T. K.: GPS radio occultation measurements of the ionosphere from CHAMP: Early results, Geophys. Res. Lett., 29(10), 95.1-95.4, doi:10.1029/2001GL014364, 2002.
Jakowski, N.: Ionospheric GPS radio occultation measurements on board CHAMP, GPS Solutions, 9(2), 88-95, 2005.

Jakowski, N., Tsybulya, K., Mielich, J., Belehaki, A., Altadill, D., Jodogne, J. C., and Zolesi, B.: Validation of GPS Radio Occultation Measurements on CHAMP by Vertical Sounding Observations in Europe, in: Earth Observation with CHAMP, Results from Three Years in Orbit, edited by: Reigber, C., Lühr, H., Schwintzer, P., and Wickert, J., Springer-Verlag Berlin, pp. 447-452, 2005.

Jakowski, N., Mayer, C., and Wilken, V.: Ionosphere Monitoring by Ground and Space Based GNSS techniques, Presenation at the FORMOSAT-3/COSMIC Workshop 2006, National Taiwan University, Taipei, Taiwan, 28 November-1 December 2006.

Jayachandran, P. T., Donovan, E. F., MacDougall, J. W., Moorcroft, D. R., St. Maurice, J.-P., and Prikryl, P.: SuperDARN Eregion backscatter boundary in the dusk-midnight sector - tracer of equatorward boundary of the auroral oval, Ann. Geophys., 20, 1899-1904, 2002, http://www.ann-geophys.net/20/1899/2002/.

Khazanov, G. V., Gamayunov, K. V., Gallagher, D. L., and Spann, J. F.: Strong pitch-angle diffusion of ring current ions in geomagnetic storm-associated conditions, J. Atmos. Sol.-Terr. Phys., 69, 142, doi:10.1016/j.jastp.2006.07.010, 2007.

Markwardt, C. and Rivers, M.: mpfit.py, http://cars9.uchicago.edu/ software/python/mpfit.html, last access November 2008.

Mende, S. B., Frey, H. U., Lampton, M., Gerard, J.-C., Hubert, B., Fuselier, S., Spann, J., Gladstone, R., and Burch, J. L.: Global observations of proton and electron auroras in a substorm, Geophys. Res. Lett., 28, 1139-1142, 2001.

Rocken, C., Kuo, Y.-H., Schreiner, W., Hunt, D., Sokolovskiy, S., and McCormick, C.: COSMIC system description, Terr. Atmos. Oceanic Sci., 11, 157-186, 2000.

Schreiner, W. S., Sokolovskiy, S. V., Rocken, C., and Hunt, D. C.: Analysis and validation of GPS/MET radio occultation data in the ionosphere, Radio Sci., 34, 949-966, 1999.

Schreiner, W., Rocken, C., Sokolovsky. S., Syndergaard, S., and Hunt, D.: Estimates of the precision of GPS radio occultations from COSMIC/FORMOSAT-3 mission, Geophys. Res. Lett., submitted, 2009.

SWACI: Space Weather Application Center Ionosphere, http:// w3swaci.dlr.de, last access 2007.

Reinisch, B. W., Nsumei, P., Huang, X., and Bilitza, D. K.: Modeling the F2 topside and plasmasphere for IRI using IMAGE/RPI and ISIS data, Adv. Space Res., 39, 731, doi:10.1016/j.asr.2006.05.032, 2007.

Szuszczewicz, E. P., Wilkinson, P., Swider, W., Pulinets, S. A., Abdu, M. A., Roelof, E., Fuller-Rowell, T., Evans, D. S., Bateman, T., and Blanchard, P.: Measurements and empirical model comparisons of F-region characteristics and auroral oval boundaries during the solstitial SUNDIAL campaign of 1987, Ann. Geophys., 11, 601-613, 1993, http://www.ann-geophys.net/11/601/1993/.

Wehrenpfennig, A., Jakowski, N., and Wickert, J.: A dynamically configurable system for operational processing of space weather data, Phys. Chem. Earth(C), 26(8), 601-604, 2001. 